\title{
Rainfall in Australia's eastern seaboard: a review of confidence in projections based on observations and physical processes
}

\author{
Andrew J. Dowdy ${ }^{1}$, Michael R. Grose ${ }^{2}$, Bertrand Timbal ${ }^{1}$, Aurel Moise ${ }^{1}$, Marie \\ Ekströ m$^{3}$, Jonas Bhend ${ }^{2}$ and Louise Wilson ${ }^{2}$ \\ ${ }^{1}$ Bureau of Meteorology, Research and Development, Docklands, Vic, Australia \\ ${ }^{2}$ CSIRO Oceans and Atmosphere, Aspendale, Vic, Australia \\ ${ }^{3}$ CSIRO Land and Water, Black Mountain, , ACT, Australia
}

(Manuscript received September 2014; accepted March 2015)

\begin{abstract}
There is a high degree of variation in rainfall projections for later this century for Australia's eastern seaboard, partly because of how different climate models represent the relevant physical processes. These processes include local environmental conditions, synoptic phenomena and large-scale atmospheric and oceanic modes of variability. We review these processes using a wide range of analyses from observations and modelling. A synthesis of this review is used to produce likelihood and confidence measures for the rainfall projections, intended to inform planning and adaptation.

The most likely projected outcome in southeast Queensland is a small decrease in rainfall for all seasons, with higher confidence in autumn than other seasons due to uncertainties associated with representing the El Niño-Southern Oscillation, thunderstorms, tropical cyclones and the monsoon. In northeast New South Wales (NSW), there is projected to be a small increase for summer, little change for autumn, a decrease for winter and a small decrease for spring, with confidence being highest in winter and lowest in summer. These projections correspond to an intensification of the annual cycle in northeast NSW. Natural variability in mean rainfall is projected to remain significant in comparison to the climate change signal throughout the eastern seaboard region. In contrast to mean rainfall, there is high confidence in a projected increase in the frequency of extreme rainfall throughout this region.
\end{abstract}

\section{Introduction}

The central eastern seaboard region encompasses river basins that drain eastward into the Pacific Ocean, including a number of important headwater catchments for a high proportion of Australia's population in the states of Queensland (QLD) and NSW. The climate of the region is primarily subtropical, with more rainfall in the warmer months than the cooler months. Phenomena such as tropical cyclones and the Australian monsoon can have a significant influence on rainfall in this region during the warmer months of the year, particularly in the more northern parts of this region. During the cooler months of the year, rainfall is often associated with phenomena such as East Coast Lows and fronts, particularly in the more southern parts of this region. The rainfall climatology of the eastern seaboard is considerably different to other parts of eastern Australia. For example, the influence of large-scale modes of variability such as the El Niño/Southern Oscillation (ENSO), the Indian Ocean Dipole (IOD) and the subtropical ridge (STR) is notably different to the region immediately to the west of the Great Dividing Range (Risbey et al. 2009; Timbal 2010; Timbal and Drosdowsky 2013; Pepler et al. 2014).

Projected changes to rainfall represent the combined influence of projected changes to all of the relevant driving influences, and this in turn relies on the realistic simulation of these influences in models. The ability to represent each of the physical processes associated with rainfall can vary between different modelling methods, including between different global climate models (GCMs) as well as between different downscaling techniques. Consequently, examining projections from a range of appropriate modelling methods can reduce the possibility of over-reliance on 
individual methods, as well as provide an indication of confidence in projections based on the degree of variation between methods.

The number of different modelling methods used is often limited by the available resources (e.g. computing time), and whilst GCMs have a global coverage, downscaling methods that provide finer resolution output typically focus only on a limited geographical domain. Comprehensive coverage of both GCM and downscaling simulations is currently limited to North America and Europe thanks to large collaborative intermodel comparison projects such as the "North American Regional Climate Change Assessment Program" (NARCCAP (Mearns et al. 2009)) and "Prediction of Regional scenarios and Uncertainties for Defining EuropeaN Climate change risks and Effects" (PRUDENCE (Jacob et al. 2007; van der Linden and Mitchell 2009)). In Australia, a set of projections has been produced for Australia by the CSIRO and Bureau of Meteorology (BoM), designed for use by Natural Resource Management (NRM) authorities through Australia (hereafter, the "NRM projections", for details see CSIRO and BoM (2015)), consisting of projections from the direct output of GCMs from the World Climate Research Program Coupled Model Intercomparison Project phase 5 (CMIP5) model archive (Meehl and Bony 2011: Taylor et al. 2012). Where downscaling could potentially provide added value, such as along the Australian eastern seaboard, GCM projections were supplemented by information from one statistical and one dynamical downscaling method (further details in the Methods section). Dynamical downscaling is also considered here based on projections produced by the New South Wales Office for Environment and Heritage; NSW/ACT Regional Climate Modelling project (NARCliM: Evans et al. (2014)).

The NRM projections of rainfall in Australia's central eastern seaboard region show a high degree of variation between different modelling methods (including between different GCMs as well as between different modelling methods (Dowdy et al. 2015; Grose et al. 2015a)), such that there is relatively high uncertainty in the rainfall projections for this region as compared to other regions throughout Australia. A wide range of factors relating to the uncertainty in these projections are examined here in order to estimate the degree of confidence that could be attached to them.

An important consideration is how well the models can reproduce the observed climate, as differences between the modelled and observed climate may indicate that the models are not adequately simulating one or more physical processes. This can lower confidence in the projections, while similarities between the modelled and observed climate may improve confidence in the projections. Stratification of model results based solely on their ability to represent particular aspects of the observed climate does not necessarily reduce uncertainty. For example, a model may not be able to adequately represent the drivers of rainfall, but may still be able to reproduce some aspects of the observed climate due to compensating errors. Therefore, a process-based evaluation can be useful to assess model simulations and confidence in projections (Risbey et al. 2002; Grose et al. 2015b).

Each of the physical processes influencing rainfall in the central eastern seaboard region has been examined in numerous previous studies, including examinations of how these influencing factors might change in the future. A survey of such studies is used here, in conjunction with analyses of observed and modelled rainfall, to provide a comprehensive examination of the degree of confidence in the projected future rainfall climatology of this region.

Methods are presented in the following section. Following this, physical processes influencing rainfall in this region are reviewed based on a broad survey of studies (relating to regional environmental conditions, synoptic systems and large-scale modes of atmospheric and oceanic variability). A range of analyses are then presented relating to the current and projected future rainfall climatologies of the region. The key points from the review and analyses are listed in Tables 1 and 2, categorised by season and region, allowing a synthesis of these points to be presented. Discussion and conclusions are presented in the final section.

\section{Methods}

The NRM projections are based on GCM results and downscaling model results. The GCM results come from the Coupled Model Intercomparison Project Phase 5 (CMIP5) model archive (Meehl and Bony 2011; Taylor et al. 2012). These climate model experiments use four concentration scenarios, described as Representative Concentration Pathways (RCPs) (Moss et al. 2010; van Vuuren et al. 2011). The focus of this study is on the high forcing case, RCP8.5, for which greenhouse gas concentrations continue to rise throughout the $21^{\text {st }}$ Century. Other scenarios are examined in some cases, including the intermediate forcing scenario RCP4.5 for which greenhouse gas concentration become stabilised later this century, as well as the low forcing scenario RCP2.6 with emissions peaking early in the century (around 2020) and then rapidly declining.

A total of 39 GCMs were used to produce the NRM projections (for details on the models, including model evaluation, see CSIRO and BoM (2015)). In addition to the direct results from the GCMs, results were also generated based on two different downscaling methods: an analoguebased statistical downscaling model (SDM) (Timbal and McAvaney 2001; Timbal et al. 2008), and a dynamical downscaling model (the Conformal Cubic Atmospheric Model, CCAM) (McGregor and Dix 2008). Since many forms of downscaling are computationally demanding, or require specific inputs, they are often run with a limited subset of GCM results as input. Consequently, the SDM results for rainfall were based on results from $22 \mathrm{GCMs}$ and the CCAM results were based on the results from $6 \mathrm{GCMs}$. For further details on these downscaling methods see CSIRO and BoM (2015). 
Table 1 Summary of rainfall analyses for southeast QLD. This information is categorised by an implied increase (blue), decrease (red) or little change (black) in rainfall, as well as by increased uncertainty (purple) in the direction of change in rainfall. Abbreviations include observations 'obs.', maximum 'max.', correlation 'corr.', east coast lows 'ECLs', tropical cyclones 'TCs', subtropical ridge 'STR', El Niño-Southern Oscillation 'ENSO' and Southern Annular Mode 'SAM'.

\begin{tabular}{|c|c|c|c|c|}
\hline & Summer & Autumn & Winter & Spring \\
\hline \multicolumn{5}{|c|}{ Physical processes: degree of influence on rainfall } \\
\hline Thunderstorms & Large & Moderate & Little & Moderate \\
\hline ECLs & Moderate & Moderate & Moderate & Moderate \\
\hline Fronts & Moderate & Moderate & Moderate & Moderate \\
\hline TCs & Large & Moderate & None & Little \\
\hline Blocking & Little or none & Little or none & Little or none & +ve corr., -ve trend \\
\hline STR & Little or none & Little or none & Little or none & Little or none \\
\hline ENSO & Large & Little or none & Large & Large \\
\hline SAM & Little or none & Little or none & Little or none & +ve corr., +ve trend \\
\hline Monsoon & Large & Some. Potential increase. & None & Moderate \\
\hline \multicolumn{5}{|l|}{ Historical rainfall } \\
\hline Seasonal cycle & GCMs similar to obs. & GCMs similar to obs. & GCMs similar to obs. & GCMs similar to obs. \\
\hline Historical trend & $\begin{array}{l}\text { Little change (GCMs) } \\
\text { Decrease (obs.) }\end{array}$ & $\begin{array}{l}\text { Little change (GCMs and } \\
\text { obs.) }\end{array}$ & $\begin{array}{l}\text { Little change (GCMs and } \\
\text { obs.) }\end{array}$ & $\begin{array}{l}\text { Little change (GCMs and } \\
\text { obs.) }\end{array}$ \\
\hline \multicolumn{5}{|c|}{ Projections for later this century } \\
\hline GCM mean rainfall & Little change or Decrease & Little change or Decrease & Little change or Decrease & Decrease \\
\hline SDM mean rainfall & Decrease & Little change or Decrease & Decrease & Increase \\
\hline CCAM mean rainfall & Little change & Little change & Increase & Little change or Decrease \\
\hline GCM heavy rainfall & Increase & Little change & Little change & Little change \\
\hline
\end{tabular}

Table 2 As for Table 1, except for northeast NSW.

\begin{tabular}{|c|c|c|c|c|}
\hline & Summer & Autumn & Winter & Spring \\
\hline \multicolumn{5}{|c|}{ Physical processes: degree of influence on rainfall } \\
\hline Thunderstorms & Large & Moderate & Moderate & Moderate \\
\hline ECLs & Large. Potential increase. & Large & Large. Potential decrease. & Moderate \\
\hline Fronts & Moderate & Large & Large. Fewer projected. & Large \\
\hline TCs & Moderate & Little & None & Very little \\
\hline Blocking & Little or none & + ve corr., + ve trend & Little or none & Little or none \\
\hline STR & + ve corr., +ve trend & Little or none & + ve corr., +ve trend & +ve corr., +ve trend \\
\hline ENSO & Large & Small. & Little or none & Small. \\
\hline SAM & Little or none & Little or none & Little or none & Little or none \\
\hline Monsoon & Some. Potential increase. & Little & None & Little \\
\hline \multicolumn{5}{|l|}{ Historical rainfall } \\
\hline Seasonal cycle & GCMs lower than obs. & GCMs lower than obs. & GCMs similar to obs. & GCMs similar to obs. \\
\hline Historical trend & $\begin{array}{l}\text { Little change (GCMs) } \\
\text { Increase (obs.) }\end{array}$ & $\begin{array}{l}\text { Little change (GCMs and } \\
\text { obs.) }\end{array}$ & $\begin{array}{l}\text { Little change (GCMs) } \\
\text { Decrease (obs.) }\end{array}$ & $\begin{array}{l}\text { Little change (GCMs and } \\
\text { obs.) }\end{array}$ \\
\hline \multicolumn{5}{|c|}{ Projections for later this century } \\
\hline GCM mean rainfall & Little change or Increase & Little change & Decrease & Little change or Decrease \\
\hline SDM mean rainfall & Decrease & Little change or Decrease & Decrease & Little change \\
\hline CCAM mean rainfall & Increase & Increase & Little change & Little change \\
\hline NARCliM mean rainfall & Increase & Increase & Little change or Decrease & Little change \\
\hline GCM heavy rainfall & Increase & Little change & Little change & Little change \\
\hline
\end{tabular}


Grose et al. (2015a) present a detailed comparison of different downscaling methods in relation to projections of future rainfall in eastern Australia. The comparison includes the SDM and CCAM projections and also those produced by the New South Wales Office for Environment and Heritage; NSW/ACT Regional Climate Modelling project (NARCliM: Evans et al. (2014)). The NARCliM projections are dynamically downscaled from four host GCMs from the previous generation of GCMs included in the CMIP3 archive using the A2 scenario (representing relatively high greenhouse gas emissions) and are included for consideration as part of the review and synthesis method presented here.

Projections are examined for two adjoining regions of the eastern seaboard as shown in Fig. 1: southeast QLD and northeast NSW. The geographic boundaries of the regions used for the NRM projections were developed in consultation with the Australian Government Department of the Environment and were informed by logical groupings of current climatic conditions, biophysical factors and expected broad patterns of climate change (e.g. CSIRO and BoM (2007)). Where possible, the boundaries were aligned with existing NRM regions.

Figure 1 Map of the two regions examined here: southeast QLD (the lightly shaded northern region comprising Fitzroy, Burnett Mary and South East Qld) and northeast NSW (the lightly shaded southern region comprising Northern Rivers, Hunter-Central Rivers and Hawkesbury-Nepean).

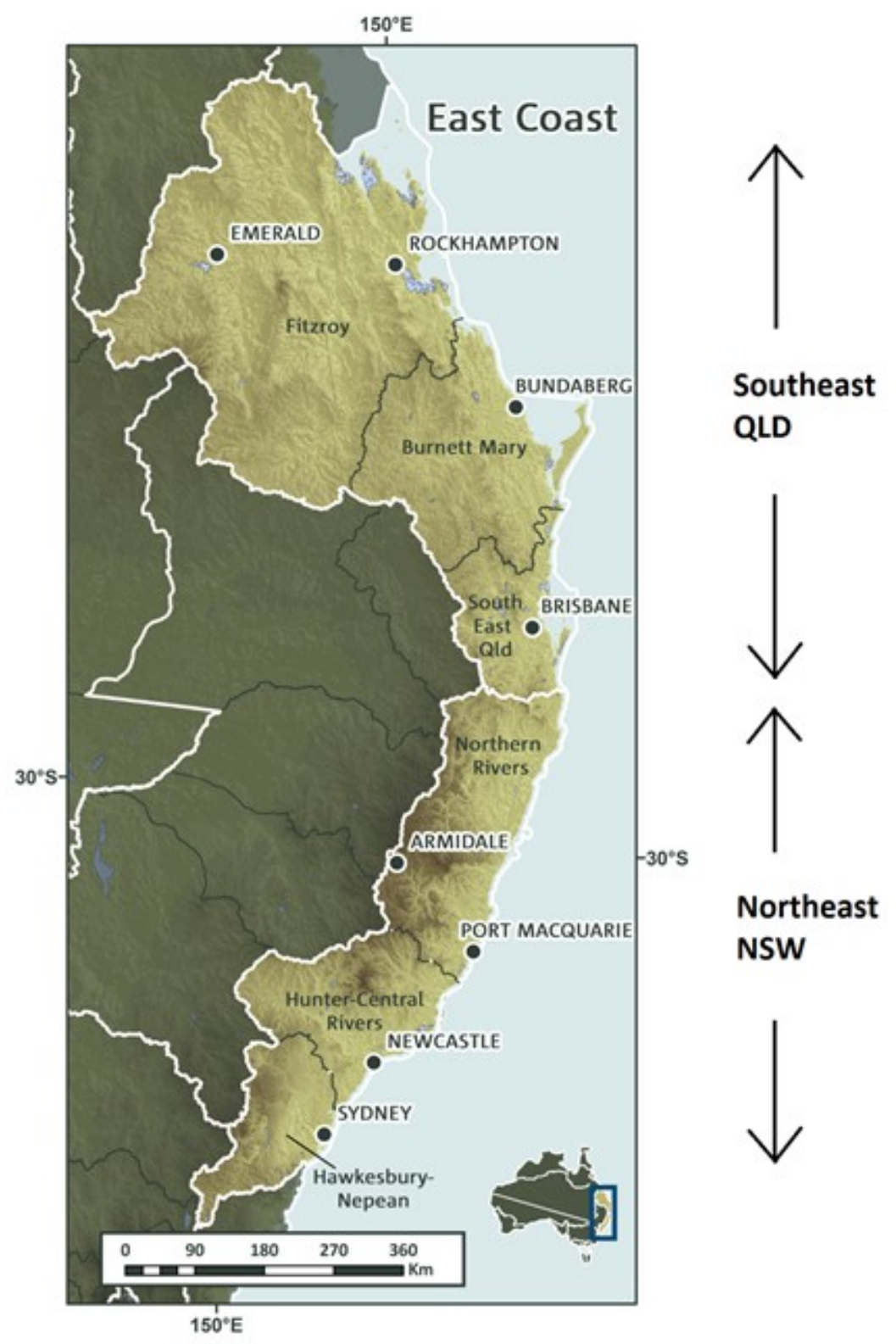


An analysis of rainfall observations makes use of the Australian Water Availability Project (AWAP) data set (Jones et al. 2009). This gridded data set is available on a 0.05 degree (about $5 \mathrm{~km}$ ) resolution in both latitude and longitude throughout Australia. AWAP provides a good representation of the spatial variability of rainfall (including extreme rainfall) in regions such as the central eastern seaboard of Australia where there is a high density of observations (e.g., King et al. (2013)). Data are fitted to a Generalised Extreme Value (GEV) distribution to examine the 20year return level of annual maximum daily rainfall (i.e., an event with a $5 \%$ average chance of occurrence per year).

Rainfall projections are examined seasonally based on three-month averages calculated for December, January and February (summer), March, April and May (autumn), June, July and August (winter) and September, October and November (spring). Confidence in the projected changes (magnitude and direction) is assessed here following the method used in the Intergovernmental Panel on Climate Change (IPCC) assessment reports (for details see Mastrandrea et al. (2010) and IPCC (2013)) based on a combination of the level of agreement between the available information (high, medium and low) and the type, amount and quality of the evidence (robust, medium and limited).

\section{Physical Processes}

A review is presented here of the primary drivers of rainfall occurrence and variability over eastern Australia, including evidence for projected changes in their occurrence due to increasing atmospheric greenhouse gas concentrations. These include a range of synoptic-scale systems, environmental phenomena and large-scale modes of atmospheric and oceanic variability.

\section{Thunderstorms}

Thunderstorms can be hazardous due to accompanying winds, hail, tornadoes, flash floods and lightning strikes, as well as having some benefits such as contributing significantly to water availability in the central eastern seaboard region. A strong annual cycle of thunderstorm activity occurs throughout Australia, with a maximum during the warmer months and a minimum during the cooler months (Kuleshov et al. 2006; Dowdy and Kuleshov 2014). The central Eastern Seaboard region experiences about 20-50 days a year on average, depending on location, which is higher than most other locations at similar latitudes throughout Australia.

The influence of global warming on thunderstorm activity in Australia is currently not well understood. In relation to severe thunderstorms, Allen et al. (2014) report a projected increase in the frequency of potential severe thunderstorm days in eastern Australia, with increases of about $14 \%$ for Brisbane and 30\% for Sydney. Some studies project a possible increase in global thunderstorm activity, while other studies do not indicate a significant change, due to considerable uncertainties associated with the current understanding of physical processes relating to thunderstorm occurrence (Williams 2005).

\section{Subtropical cyclones (East Coast Lows)}

East Coast Lows (ECLs) are intense baroclinic low pressure systems that occur in the vicinity of eastern Australia, often associated with severe weather such as heavy rainfall, strong winds and large ocean waves. This definition presented here is based in part on some of the common elements from various different definitions used in previous studies (e.g., Hopkins and Holland (1997); Speer et al. (2009); Mills et al. (2010)). Although ECLs are extratropical cyclones, they are typically cut-off from (i.e. not embedded within) the extratropical storm track region poleward of the subtropical ridge, with subtropical eastern Australia being a favoured location for ECL occurrence (Dowdy et al. 2013a). ECLs often have a low-level thermal asymmetry such that the strongest pressure gradients (and therefore winds) occur on the poleward side of the st orm (Mills et al. 2010), and consequently they are the primary driver of the strong onshore winds and large storm waves that occur along the central east coast of Australia (Dowdy et al. 2014). In spite of this low-level thermal asymmetry, these systems are baroclinic, developing in response to deep tropospheric potential vorticity advection (Dowdy et al. 2013b).

ECLs are associated with a high proportion of heavy rainfall events (e.g., they account for about 50-80\% of extreme rainfall events in the central eastern seaboard region (Dowdy et al. 2013c)). The cooler months of the year have the largest proportion of heavy rainfall attributed to ECLs and there is some indication of a significant correlation between winter rainfall associated with ECLs and the Southern Annular Mode (Pepler et al. 2014). Projections from CMIP5 GCMs indicate about 40\% fewer ECLs towards the end of this century for RCP 8.5 and $20 \%$ fewer for RCP4.5 (Dowdy et al. 2014). The NARCliM downscaling projections (based on CMIP3 GCMs) indicate that the reduction in the number of ECLs is likely to occur primarily during the cooler months of the year, with little change during summer (Ji et al. 2015). Although fewer ECLs are projected to occur, those that do occur could potentially produce heavier rainfall in some cases (e.g., based on increased moisture availability as indicated by the Clausius-Clapeyron relation with increasing temperatures) such that there is currently not a high degree of confidence in projections of mean rainfall associated with ECL occurrence. However, the potential increase in rainfall intensity produced by some ECLs, combined with projections of little change in ECL frequency during summer, provides some indication of a potential increase in rainfall associated with ECL occurrence during summer. 


\section{Fronts}

Fronts are a common cause of rainfall in the central eastern seaboard of Australia, particularly in the southern parts of the region during the cooler months of the year (e.g. Catto and Pfahl (2013)). The frequency of fronts and the proportion of rainfall associated with fronts can be simulated well by GCMs (while noting that the intensity of the rainfall is underestimated in many regions). Projections indicate a decrease in the number of fronts and frontal rain in southern Australia during the cooler months (Catto et al. 2013). The results are less clear during the warmer months of the year and in other parts of Australia.

\section{Tropical cyclones}

Tropical cyclones (TCs) can have severe impacts on the Eastern Seaboard region (e.g. through the occurrence of extreme rainfall events) as well contributing significantly to annual mean rainfall amounts in northern Australia (Lavender and Abbs 2013). The mean number of TCs is 11 per year in the Australian region (from $90-160^{\circ} \mathrm{E}$ ) and 4 per year in the eastern Australian region (from $142.5-160^{\circ} \mathrm{E}$ ). These values are based on the time period from the $1981 / 1982$ wet season to the $2012 / 2013$ wet season, as this time period is unlikely to have significant satellite-induced inhomogeneities (as discussed by Dowdy and Kuleshov (2012)).

A recent study found a downward trend in the number of TCs in the Australian region based on high-quality observations, with the trend being significant at the 93-98\% confidence level (Dowdy 2014). This is broadly consistent with previous studies such as Nicholls et al. (1998), who presented a decline in TC numbers near Australia using observations from the 1969/1970 to 1995/1996 seasons, although it is noted that satellite data inhomogeneities during the early part of this time period could potentially have a significant influence on trend analys es (as discussed by Kuleshov et al. (2010)). Callaghan and Power (2010) report a decreasing trend in the number of severe TCs making landfall south of Port Douglas in eastern Australia, significant at the $90 \%$ level (based on reports from numerous historical sources, including peer-reviewed publications, newspapers and sea-faring observations dating back to the late $19^{\text {th }}$ Century).

Modelling studies generally suggest fewer, but potentially more intense, TCs could be expected to occur in a warmer world on a global scale (Knutson et al. 2010). Although there is considerable uncertainty associated with projections of future tropical cyclone intensity in eastern Australia (including the intense rainfall produced by TCs), there is considerable agreement between observations and modelling studies in indicating a reduction in the frequency of occurrence of TCs in this region.

\section{Atmospheric blocking}

Persistent high-pressure cells that occur in the Tasman Sea, known as blocking highs, can act on fronts and lows embedded in the westerly flow to steer them southwards away from southern Australia (Pook and Gibson 1999; Pook et al. 2013). In eastern Australia, the occurrence of blocking events shows some relationship (positive correlation) to rainfall in spring for southeast QLD and in autumn for northeast NSW (Risbey et al. 2009; Pook et al. 2013). Grose et al. (2012) report a projected decrease during winter and spring, as well as an increase during summer and autumn, in the frequency of blocking in the Tasman Sea towards the end of this century due to increasing greenhouse gas concentrations (while noting that this was based on CCAM downscaling from one GCM and consequently may not represent a comprehensive range of plausible outcomes).

\section{Subtropical Ridge}

The subtropical ridge (STR) is a zone of high pressure in mid-latitude regions associated with the boundary between the prevailing westerly wind regime to the south and the south-easterly trade winds to the north. The intensity of the STR is related (positive correlation) to observed rainfall in northeast NSW during all four seasons (while noting a relatively weak relationship during autumn), with relatively little relationship to rainfall in southeast QLD during any season, and there is an indication of a long-term trend towards increased STR intensity (higher pressure) in the wider Australian region (Timbal and Drosdowsky 2013; Nguyen et al. 2013). GCMs generally project that the intensity of the STR in the Southern Hemisphere is likely to increase over the $21^{\text {st }}$ Century, whilst its mean position is likely to be further south, while noting considerable uncertainty in projected future changes to the STR (Drosdowsky 2005; Kent et al. 2013; Grose et al. 2015b).

\section{ENSO}

ENSO is an ocean-atmosphere coupled mode, with strong interaction between the Walker Circulation and the Pacific Ocean. The relationship between ENSO and Australian climate variability has long been known (e.g., McBride and Nicholls (1983)). In the central eastern seaboard of Australia, more rainfall typically occurs during La Niña than El Niño conditions (Risbey et al. 2009). For example, the Southern Oscillation Index (SOI) is significantly related to rainfall in large parts of southeast QLD during summer, winter and spring, as well as during autumn to a somewhat lesser degree. For northeast NSW, the SOI shows a strong relationship to rainfall during summer, a weak relationship during autumn and spring, and almost no relationship during winter. 
Although there is considerable uncertainty associated with long-term changes in ENSO, the Walker Circulation shows signs that it has weakened during the $20^{\text {th }}$ Century (Power and Kociuba 2011) and due to an increase in moisture availability it is likely that ENSO-related precipitation variability on regional scales will intensify (Chapter 12 in IPCC (2013)). CMIP5 models are generally better at representing ENSO than CMIP3 models (Guilyardi et al. 2009), while noting that current GCMs still have considerable limitations such as in their ability to represent rainfall teleconnections in some regions (Watanabe et al. 2012).

\section{SAM}

The Southern Annular Mode (SAM), describing the alternation of atmospheric mass between high- and mid-latitudes, is a dominant driver of large-scale climate variability in the mid- and high-latitudes of the Southern Hemisphere through its relationship to pressure, wind and rainfall patterns (Thompson and Solomon 2002). The positive phase of SAM is characterised by a poleward contraction of the midlatitude westerlies. Rainfall in the central eastern seaboard is related to SAM during spring, particularly for southeast QLD (positive correlation), with little relationship during other seasons (Risbey et al. 2009).

The southward contraction of SAM (i.e. a trend toward an increasingly positive phase) in recent decades can be attributed to atmospheric greenhouse gas increases, as well as to stratospheric ozone decreases (particularly during summer), noting that stratospheric ozone depletion is expected to stabilise and possibly recover in coming decades but that greenhouse gas forcing is likely to increase (Gillett and Thompson 2003; Arblaster and Meehl 2006; Son et al. 2010). CMIP5 models are able to produce a clear SAM (Raphael and Holland 2006) but there are relatively large differences between models in terms of the exact shape and orientation of this pattern.

\section{IOD}

The Indian Ocean zonal dipole mode (IOD) is a coupled ocean-atmosphere phenomenon located in the tropical Indian Ocean. It is usually active from May to November and is often terminated by the wind reversal accompanying the arrival of the monsoon in northern Australia. The IOD generally has a weak relationship to rainfall in southeast QLD and northeast NSW (Risbey et al. 2009).

Most CMIP3 and CMIP5 models are able to reproduce the general features of the IOD but show a large spread in the strength of the IOD and some bias in the westward extension of the IOD (Saji et al. 2006; Liu et al. 2011; Cai and Cowan, 2013). The overall frequency of IOD events (positive and negative) is not projected to change (IPCC 2013), although the IOD is projected to change in ways more characteristic of a typical positive IOD event - cooler temperatures across the eastern Indian Ocean and warmer in the western Indian Ocean during spring (Cai et al. 2013).

\section{Australian Monsoon}

The Australian monsoon is characterised by an annual reversal of the low level winds and well defined dry and wet seasons, driven by the summer heating of the Australian continent and the resulting change in land-sea temperature gradients (Wang and Ding 2008; Moise et al. 2012). On the seasonal time-scale, most of the northern tropical regions experience a wet summer period and a dry winter period, with this contrast between the two seasons decreasing further to the south as the influence of the Australian monsoon decreases (i.e. more relevant for southeast QLD than northeast NSW). Although the bulk of the wet season rainfall occurs after the reorganisation of the circulation at monsoon onset, a significant proportion (above about 30\%) of the wet season rainfall occurs prior to onset during the period from about September to November (Nicholls et al. 1982), with this 'transition season' of pre-monsoon rainfall being characterised by increased frequency of squall lines and thunderstorms (Troup 1961).

The previous generation of GCMs (CMIP3) generally did not produce a good representation of the primary characteristics of the monsoon (Randall et al. 2007), with some improvements being noted in the current generation of GCMs (CMIP5) including with respect to its mean climate, annual cycle and interannual variability (Sperber et al. 2013). Although there is considerable uncertainty in projected changes to monsoonal activity on regional scales, on the global scale the geographical region affected by monsoons is projected to increase over the $21^{\text {st }}$ Century, together with monsoon rainfall, while monsoon winds are projected to weaken due to a slowing of the global tropical circulation (Chapter 12 in IPCC 2013). Additionally, monsoon onset dates are projected to become earlier or not to change much and monsoon retreat dates are projected to become later.

\section{Rainfall Climatologies}

\section{Current climatology of mean rainfall}

The annual cycle of rainfall as simulated by the GCMs is shown in Fig. 2 compared to that based on observations (from AWAP) for the period 1986 to 2005. Observed rainfall is summer-dominated in both regions (for southeast QLD and northeast NSW), with winter being the driest 
season. The model ensemble median values provide an accurate representation of the annual cycle in both regions with the exception of northeast NSW during summer and autumn (from about January to May) for which most models tend to underestimate the observed rainfall.

Figure 3 shows the standard deviation of rainfall (mm per day) for the entire East Coast region (i.e. the sum of the southeast QLD and northeast NSW regions). This is shown as simulated by individual GCMs, as well as based on observations (from AWAP), for the period 1986 to 2005. About two thirds (one third) of the GCMs have values lower (higher) than that based on observations. The $10^{\text {th }}$ to $90^{\text {th }}$ percentile range of the model ensemble encompasses the value based on observations.

Figure 2 The annual cycle of rainfall for the current climate (i.e. the period 1986-2005): southeast QLD (a) and northeast NSW (b), based on observations (AWAP: purple line), individual model results (grey lines) and GCM ensemble median (black line).

\section{(a) Southeast QLD}

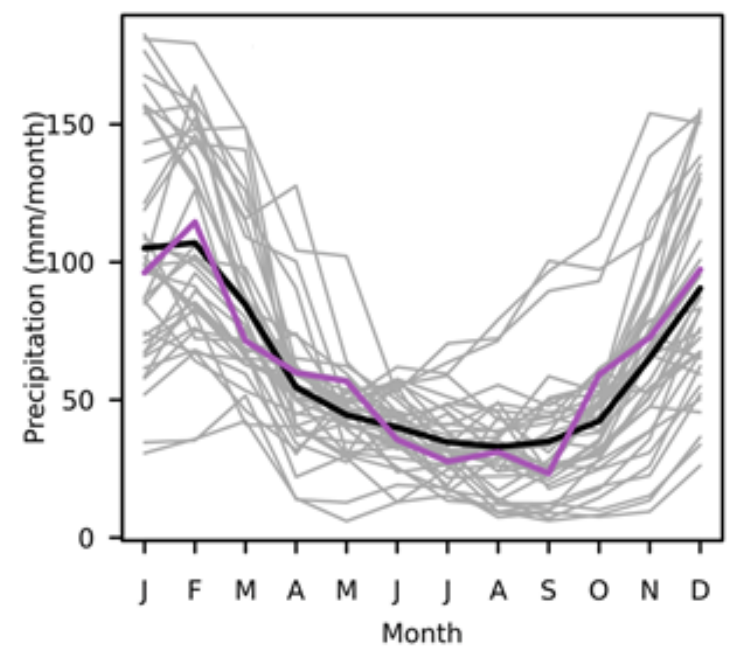

(b) Northeast NSW

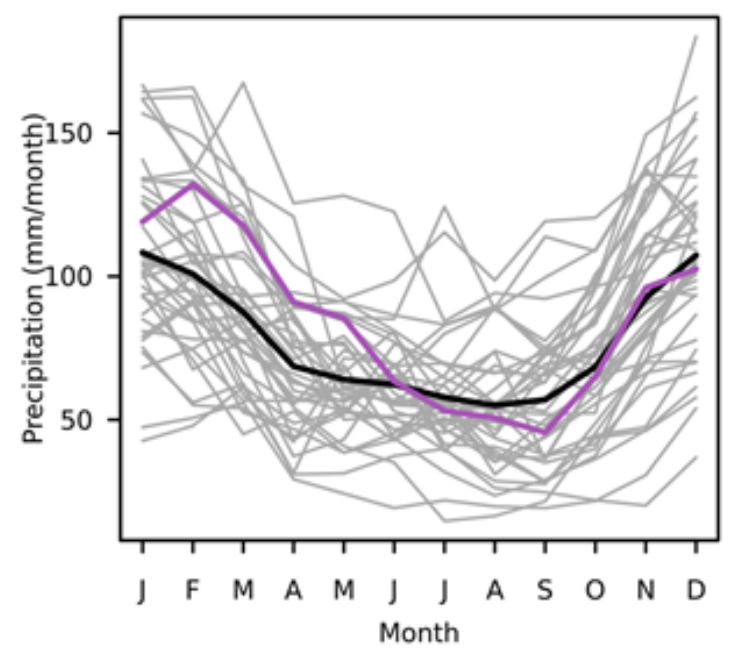

Figure 3 Standard deviation of rainfall $\left(\mathrm{mm} \mathrm{day}^{-1}\right)$ for the entire East Coast region (i.e. the sum of the southeast QLD and northeast NSW regions). This is shown as simulated by individual CMIP5 GCMs (blue), as well as based on observations from AWAP (red), for the period 1950-2005.

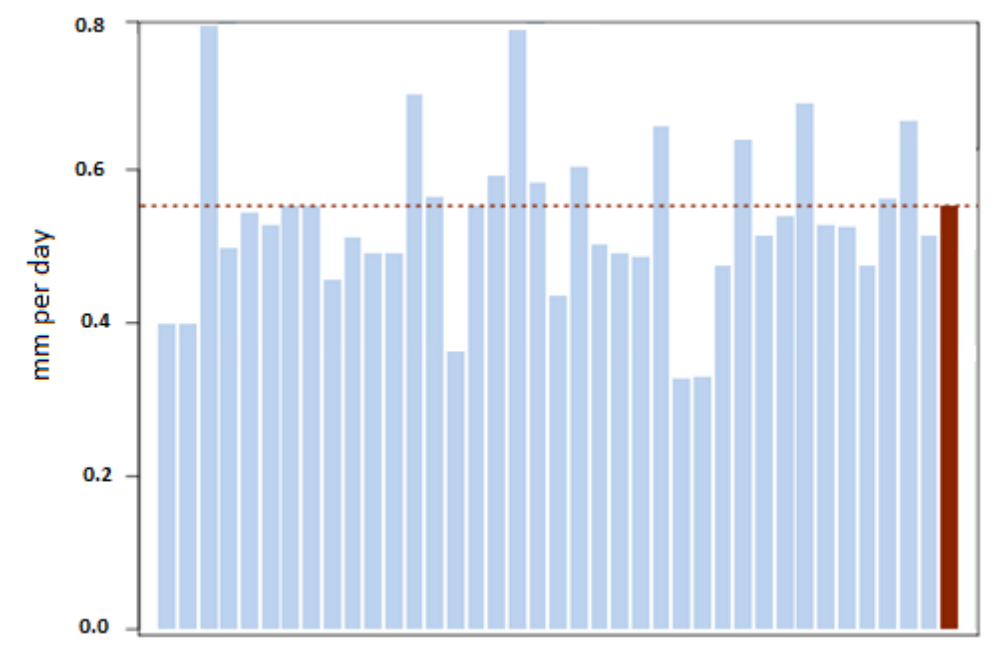

Annual rainfall anomalies from 1901 to 2013 (relative to the 1986 to 2005 mean) show that the region has experienced a considerable degree of variation in rainfall during this period (Fig. 4). There is no long-term trend in either southeast QLD or northeast NSW that is significant at any meaningful confidence level. During much of the early part of the $20^{\text {th }}$ Century, eastern Australia experienced extensive drying, including the Federation Drought at the start of the century (from about 1895-1902) and the World War II Drought a few decades later from 1935-1945. The 
latter part of the $20^{\text {th }}$ Century saw a continuation of these variable conditions. The $21^{\text {st }}$ Century began with a period of below average years. This was followed by a period of above average rainfall, with the highest annual rainfall during the entire period of data occurring during 2010 in southeast QLD, relating to a strong La Niña event. In contrast, although northeast NSW rainfall in 2010 was above average, it was not a record.

Long-term changes (from 1910 to 2005) in seasonal (3-month average) rainfall are shown in Fig. 5. For southeast QLD, there is some indication of a small decrease in observed summer rainfall, with no notable change for other seasons. The GCM ensemble median values indicate no change in any season. For northeast NSW, there is some indication of a small increase in summer and a small decrease in winter, with little or no notable change in autumn and spring. The GCM median values again indicate no trends in any season.

Figure 4 Annual rainfall anomalies (mm) relative to the 1986-2005 mean, shown from 1901 to 2013 for (a) southeast QLD and (b) northeast NSW, based on an analysis of observed data (AWAP). An 11-year running mean is shown.

\section{(a) Southeast QLD}

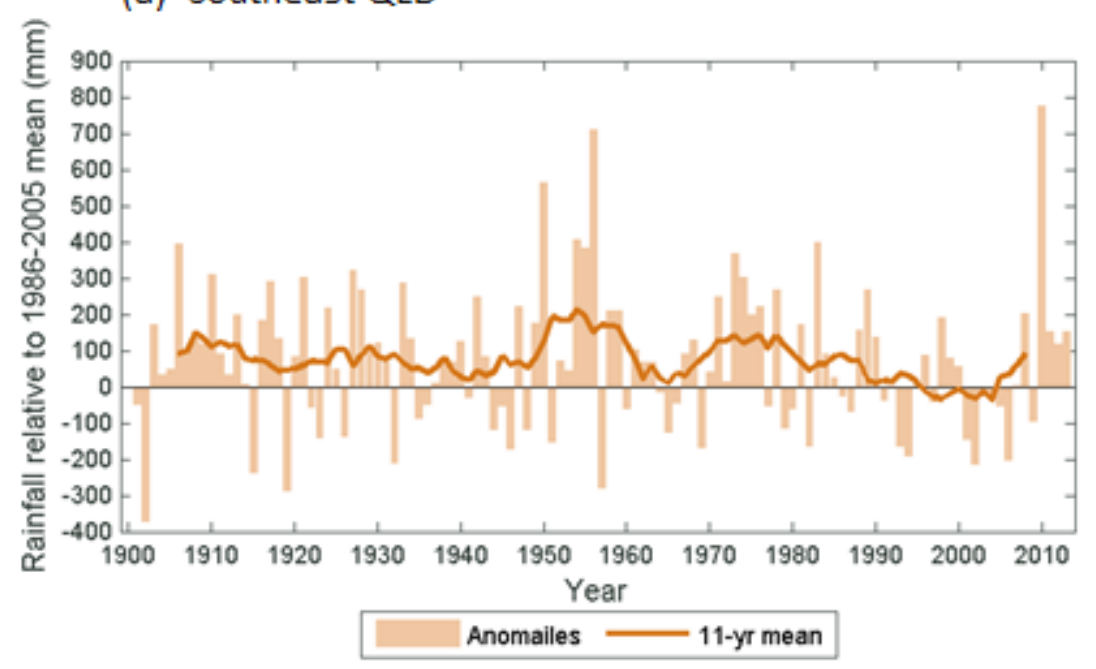

(b) Northeast NSW

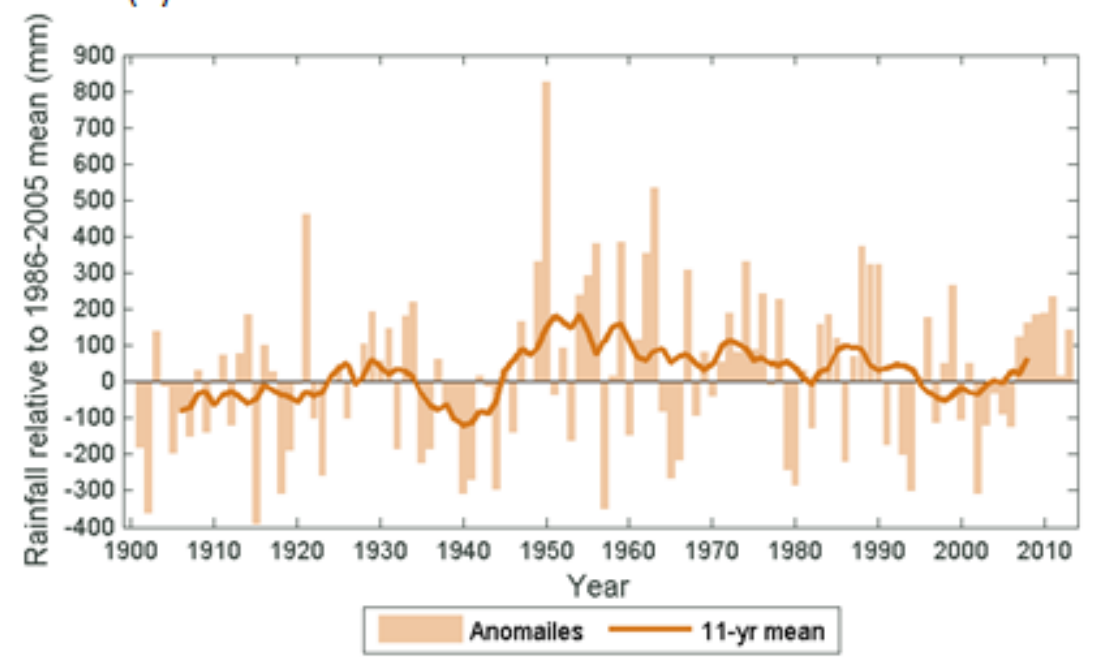


Figure 5 Rainfall trends (mm per decade) for the period from 1910 to 2005 for (a) southeast QLD and (b) northeast NSW. This is shown for three month average values, based on observations (AWAP: purple line), as well as based on GCM simulations for individual models (grey lines) and the model ensemble median (black line).

\section{(a) Southeast QLD}

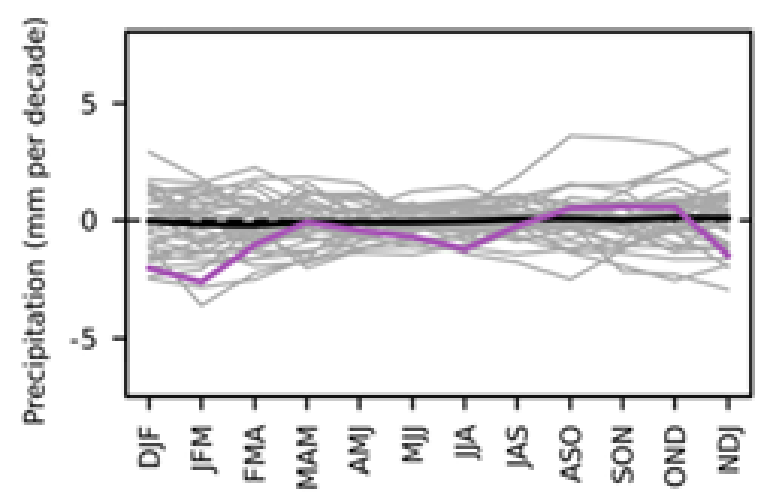

(b) Northeast NSW

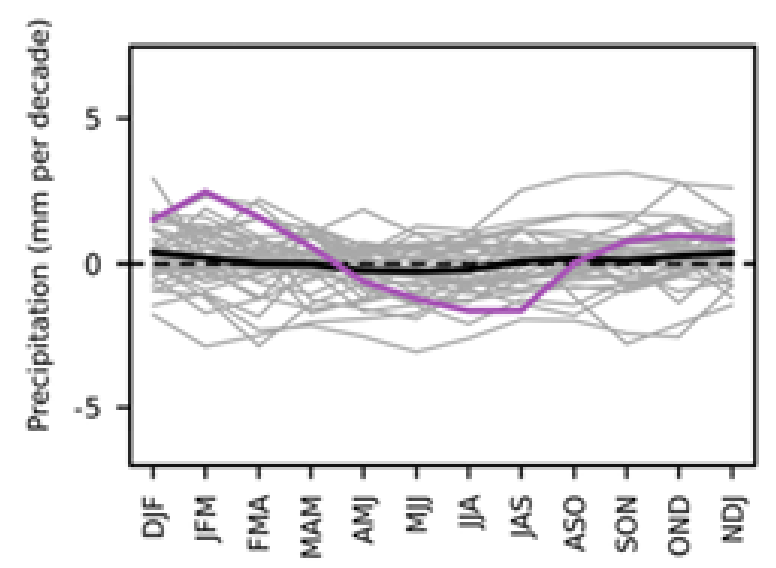

\section{GCM projections of mean rainfall}

Ensemble mean annual rainfall anomalies over the period 1910 to 2090 are shown in Fig. 6. For southeast QLD, the $10^{\text {th }}$ to $90^{\text {th }}$ percentiles of the GCM ensemble encompass a range of projected outcomes, from a decrease to a small increase in 20 -year average rainfall. The ensemble median indicates that more than half of the models simulate a reduction in rainfall, while noting that the reduction is relatively small in magnitude compared to the degree of interannual variability in the observed climatology. For northeast NSW, the GCM ensemble range includes both increases and decreases of relatively small magnitude compared to the range of inter-annual variability in the observed climatology, with the median projection indicating little or no change.

The variability in annual rainfall as simulated by a single GCM (ACCESS1-0) is also shown in Fig. 6, providing an indication of the natural variability from year-to-year as simulated by the models. Additionally, the light shaded areas in Fig. 6 show the $10^{\text {th }}$ to $90^{\text {th }}$ percentile range of the GCM simulations of annual rainfall. The annual rainfall variability as simulated by the GCMs towards the end of the century is similar in magnitude to that of the observations (based on AWAP), indicating that natural variability in annual rainfall (i.e. the frequency of wet and dry years) is likely to remain strong compared to any anthropogenic climate change signal towards the end of the $21^{\text {st }}$ Century. This is the case for both southeast QLD and northeast NSW. 
Figure 6 Simulated and observed annual rainfall anomalies (\%) from 1910 to 2090 (relative to the 1950-2005 baseline) for the RCP8.5 emissions scenario, shown for southeast QLD (a) and northeast NSW (b). The dark shaded areas show the $10^{\text {th }}$ to $90^{\text {th }}$ percentile range, and the middle (bold) line the median, for the GCM simulations of 20-year average rainfall. The light shaded areas show the $10^{\text {th }}$ to $90^{\text {th }}$ percentile range of the GCM simulations of annual rainfall. Annual rainfall is also shown for the historical climate based on observations (AWAP) and the projected future climate based on a single GCM (ACCESS1 -0).

(a) Southeast QLD

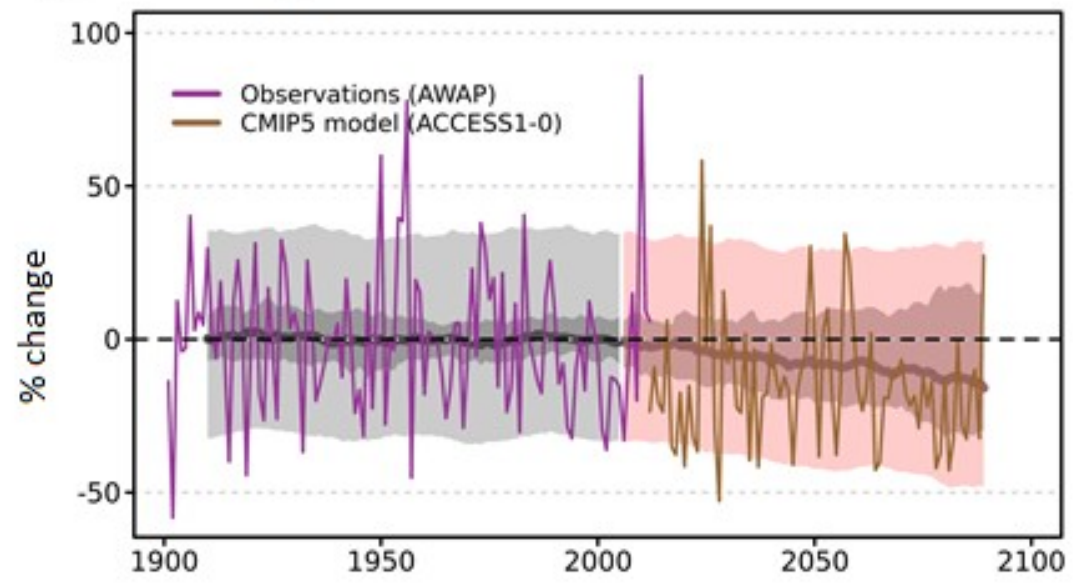

(b) Northeast NSW

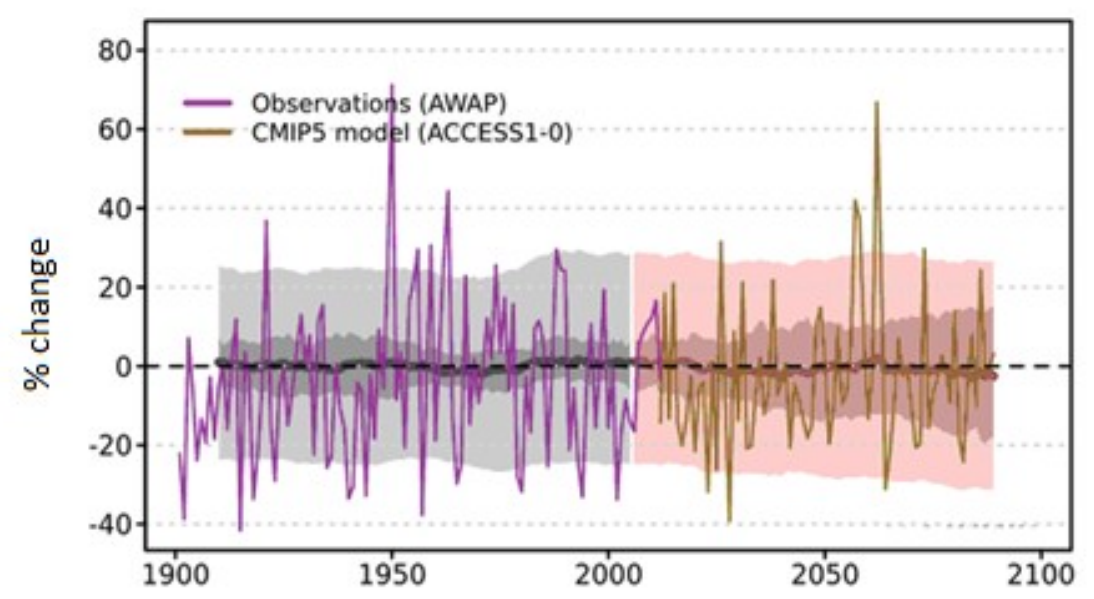

Seasonal projected changes (for the period 2080-2099 compared to 1986-2005) are presented in Fig. 7 for a range of different emission scenarios. In southeast QLD, the GCM ensemble of projections encompasses both increases and decreases for each season. Median values for the RCP8.5 scenario are less than zero in all four seasons, while noting that the magnitude of the change is close to zero during summer. It is only during spring that the $90^{\text {th }}$ percentile values are close to zero, indicating a considerable degree of agreement in the direction of change projected by the models for this season. The projected changes for the other emission scenarios (RCP4.5 and RCP2.6) are generally similar in sign but smaller in magnitude than those for the RCP 8.5 scenario. The projected changes are relatively small for all three scenarios during the early $21^{\text {st }}$ Century (2020-2039), being 10\% or less in each season and region (Table 3).

For northeast NSW towards the end of the $21^{\text {st }}$ Century, the GCM ensemble of projections includes both increases and decreases for each season. The median values for the RCP8.5 scenario indicate a small increase in summer rainfall, little or no change during autumn, a reduction during winter and a small reduction during spring. The projected reductions during winter and spring contrast with projected summer increases, such that there is little or no projected change in annual rainfall for northeast NSW (as was seen from Fig. 6). During winter, the $10^{\text {th }}$ to $90^{\text {th }}$ percentile range of the GCM ensemble is relatively small compared with the other cases shown in Fig. 7. There is a notable decrease in the GCM ensemble median, and only about $10 \%$ of models indicate an increase, suggesting a considerable degree of model agreement for this case. 
Table 3 Projected change in seasonal rainfall (in \%) for southeast QLD and northeast NSW based on the GCM simulations. Changes are shown for the 2020 to 2039 (2030) and 2080 to 2099 (2090) periods relative to the 1986 to 2005 period, for the low (RCP2.6), intermediate (RCP4.5) and high (RCP8.5) emission scenarios. The median value is shown, with the $10^{\text {th }}$ and $90^{\text {th }}$ percentiles in brackets.

\begin{tabular}{llllllll}
\hline Region & Season & $2030, R C P 2.6$ & $2030, R C P 4.5$ & $2030, R C P 8.5$ & $2090, R C P 2.6$ & $2090, R C P 4.5$ & $2090, R C P 8.5$ \\
\hline \multirow{3}{*}{$\begin{array}{l}\text { South-east } \\
\text { QLD }\end{array}$} & Summer & $-1(-14$ to 21$)$ & $-5(-17$ to 16$)$ & $-5(-18$ to 16$)$ & $-6(-25$ to 11$)$ & $-5(-22$ to 11$)$ & $-6(-29$ to 28$)$ \\
& Autumn & $-6(-23$ to 29$)$ & $-5(-23$ to 15$)$ & $-8(-21$ to 12$)$ & $-8(-30$ to 18$)$ & $-6(-28$ to 19$)$ & $-12(-36$ to 30$)$ \\
& Winter & $-5(-26$ to 12$)$ & $-5(-27$ to 8$)$ & $-10(-34$ to 14$)$ & $-3(-29$ to 6$)$ & $-12(-35$ to 7$)$ & $-17(-49$ to 18$)$ \\
& Spring & $-2(-28$ to 15$)$ & $-5(-23$ to 16$)$ & $-8(-29$ to 11$)$ & $-4(-32$ to 16$)$ & $-14(-36$ to 5$)$ & $-28(-53$ to 3$)$ \\
\hline \multirow{4}{*}{$\begin{array}{l}\text { North-east }) \\
\text { NSW }\end{array}$} & Summer & $1(-13$ to 18$)$ & $1(-10$ to 15$)$ & $2(-13$ to 14$)$ & $-2(-22$ to 10$)$ & $0(-15$ to 19$)$ & $11(-12$ to 27$)$ \\
& Autumn & $-2(-16$ to 8$)$ & $-3(-22$ to 15$)$ & $-3(-13$ to 14$)$ & $-6(-23$ to 12$)$ & $-1(-22$ to 18$)$ & $-2(-28$ to 20$)$ \\
& Winter & $-2(-19$ to 10$)$ & $-5(-18$ to 14$)$ & $-8(-20$ to 12$)$ & $-3(-16$ to 8$)$ & $-8(-24$ to 7$)$ & $-17(-31$ to 1$)$ \\
& Spring & $-3(-18$ to 18$)$ & $-1(-19$ to 12$)$ & $-3(-20$ to 11$)$ & $0(-19$ to 10$)$ & $-6(-23$ to 9$)$ & $-8(-30$ to 14$)$ \\
\hline
\end{tabular}

Figure 7 Projected seasonal rainfall changes (\%) for the period 2080-2099 compared to the period 1986-2005, shown for southeast QLD (a) and northeast NSW (b). The horizontal bar is the median, and the shaded region is the 10th to 90th percentile range, for the GCM simulations. The narrow vertical lines represent the 10th to 90th percentile range based on the GCM simulations for individual years. Projections are shown for low (green: RCP2.6), intermediate (blue: RCP4.5) and high (purple: RCP8.5) emission scenarios. Natural variability as represented by the GCMs is shown in grey for the current climate (during the period 1986-2005).

(a) Southeast QLD

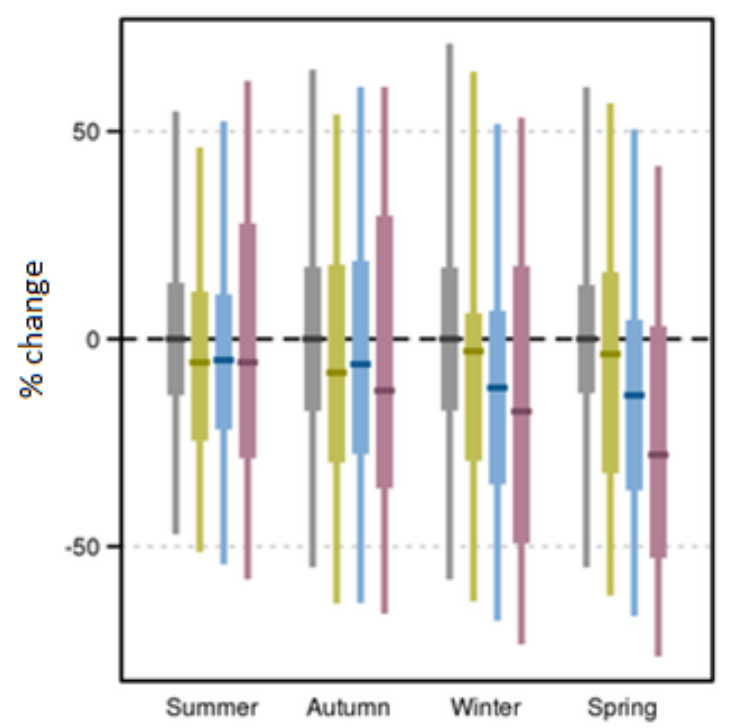

(b) Northeast NSW

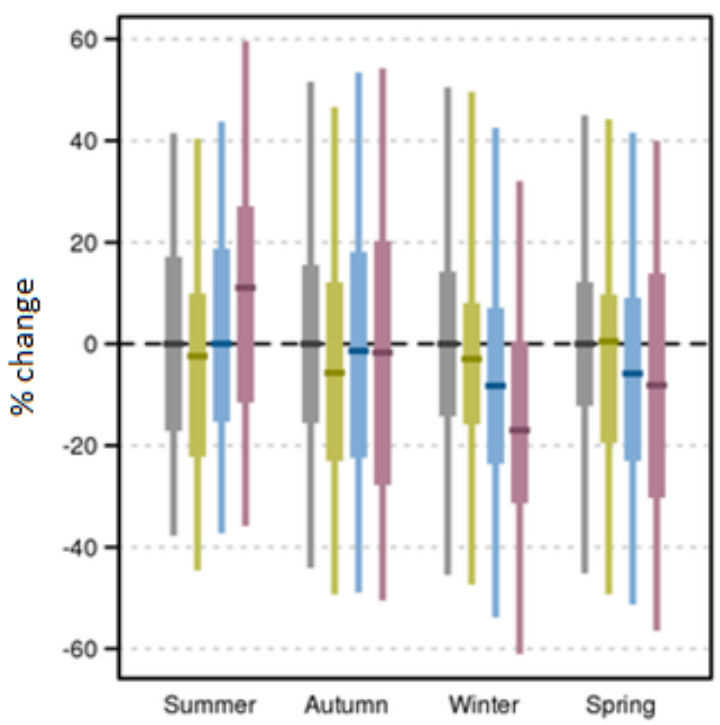

There are only two cases (spring in southeast QLD and winter in northeast NSW) where the GCM ensemble median is notably different to the range of natural variability in the current climate (as indicated by the $10^{\text {th }}$ to $90^{\text {th }}$ percentile range of the GCM ensemble for the period 19862005). However, there is considerable variation between models in all cases, with some that project increases and others that project decreases in all four seasons for both regions.

The seasonal rainfall projections for this region (from Fig. 7) are broadly similar to those based on the previous set of GCMs (the CMIP3 set of GCMs, for a relatively high emission scenario 'A2'), including similarities in relation to the relatively large variation between models in this region (CSIRO and BoM 2007). A large variation between model projections was also noted in a recent investigation for southeast Queensland 
(Smith et al. 2013) which indicated that CMIP5 multi-model mean projected changes in rainfall were not statistically significant for any season or annually.

\section{Downscaling projections}

Projected changes in seasonal precipitation are shown in Figure 8 for two different downscaling methods: the SDM downscaling from 22 host GCMs, and the CCAM downscaling from 6 host GCMs. The projections are for 2080-99 with respect to 1986-2005, based on RCP8.5.

The SDM projections for southeast QLD during autumn and winter are broadly consistent with the direct output from the host GCMs based on the ensemble median (Fig. 8). During summer, the SDM indicates a decrease with a high model agreement in contrast to little or no change as projected by the host GCMs, and during spring the SDM projections indicate an increase in strong contrast to the decrease projected by the GCMs. Similarly for northeast NSW, the SDM projections during autumn and winter are broadly similar to those of the GCMs, but notably lower (higher) than the direct model output during summer (spring).

The CCAM projections for southeast QLD are broadly consistent with those of the host GCMs for all seasons with the exception of winter for which CCAM indicates an increase in rainfall in contrast to the decrease indicated by the GCM output (Fig. 8). In northeast NSW, CCAM projections are broadly consistent with those of the direct model output during spring, but indicate a higher amount of rainfall during summer, autumn and winter than the GCMs. This tendency for CCAM to indicate more winter (autumn) rainfall than the GCMs is a consistent result throughout the tropical (mid-latitude) regions of Australia (CSIRO and BoM 2015).

The NARCliM projections of future rainfall for northeast NSW were shown by Grose et al. (2015a) to be broadly consistent with the other modelling methods examined here in that there is considerable variation between different modelling configurations, while noting some indication of a small increase for summer and autumn, little change or a small decrease for winter and little change for spring.

\section{Rainfall intensity}

Projections of annual mean rainfall, annual maximum daily rainfall and the 20-year return level of annual maximum daily rainfall are shown in Fig. 9. In contrast to the case for mean rainfall, there is a clear increase in the projected intensity of the 20 -year return level for RCP8.5 in both southeast QLD and northeast NSW, with a high level of agreement between models in the direction of change. The projected increases relate to summer rainfall in both regions, with relatively little change for other seasons. The projected changes for RCP4.5 are generally similar in direction to the case for RCP8.5 but smaller in magnitude.

Precipitation extremes are generally expected to increase in magnitude in a warming climate (e.g., relating to the Clausius-Clapeyron relation, as discussed by studies such as Sherwood et al. (2010) and Min et al. (2011)). However, it is noted that there are a wide range of physical processes that influence rainfall occurrence in this region. For example, changes in the intensity or occurrence frequency of processes such as those examined in the review Section could potentially offset or enhance the projected changes in extreme rainfall indicated by the ClausiusClapeyron relation.

\section{Synthesis}

Tables 1 and 2 summarise the various factors discussed in this study relating to the current and future seasonal rainfall climatologies of southeast QLD and northeast NSW, respectively. This information is categorised based on whether it implies a projected increase (blue), little change (black) or decrease (red) in rainfall, or if it notably adds to the degree of uncertainty in the projections (purple). A synthesis of this information is used here to produce confidence estimates in the projections.

Likelihood estimates for three different projected outcomes (Increase, Little change or Decrease) are shown in Table 4, based on a consider ation of all information presented in Tables 1 and 2. The projected outcomes are for the time period towards the end of the $21^{\text {st }}$ Century, under moderate to strong greenhouse gas forcing. The likelihood descriptors represent estimates of probabilities of outcome, as shown by percentages in Table 4, following the method of IPCC (2013).

The most likely projected outcome is presented in Table 5 based on consideration of the likelihood estimates for each of the three different projected outcomes (from Table 4). The magnitude of the most likely projected outcome is described as little change if the magnitude is less than $5 \%$, small increase or small decrease if the magnitude is within the range 5-15\% and increase or decrease if the magnitude is greater than $15 \%$.

Confidence estimates in the most likely projected outcome are determined by combining the level of agreement between the available information (high, medium and low) and the type, amount and quality of the information (robust, medium and limited), based on all information presented in Tables 1 and 2. This method is similar to that used by the IPCC (for details see Mastrandrea et al. (2010)), although due to the considerable uncertainties in the rainfall projections for this region, the high category for agreement and the robust category for evidence are not appli- 
cable and intermediary categories are added between the lower and middle categories of agreement and evidence. This results in five levels of confidence as shown in Table 5, ranging from Very Low confidence to Medium confidence.

Figure 8 Projected changes (\%) in seasonal precipitation for different downscaling methods. The projections are for 2080-99 with respect to 1986-2005, based on RCP8.5, for southeast QLD (a) and northeast NSW (b). For each season, projections are shown for the CMIP5 ensemble (based on $39 \mathrm{GCMs}$ ), SDM downscaling from 22 host GCMs, and CCAM downscaling from 6 host GCMs. The central horizontal bar represents the median value, and the shaded region the 10th to 90th percentile range, of the simulations of ra infall averaged for the respective time periods. The narrow vertical lines represent the 10th to 90th percentile range based on the simulations of annual rainfall.

(a) Southeast QLD

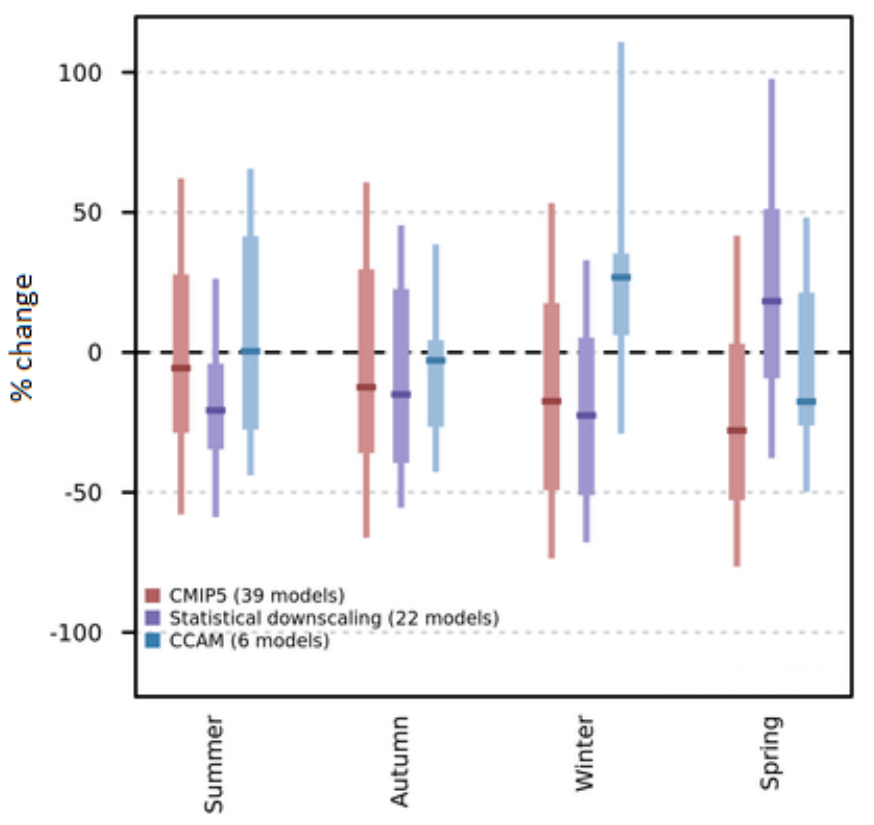

(b) Northeast NSW

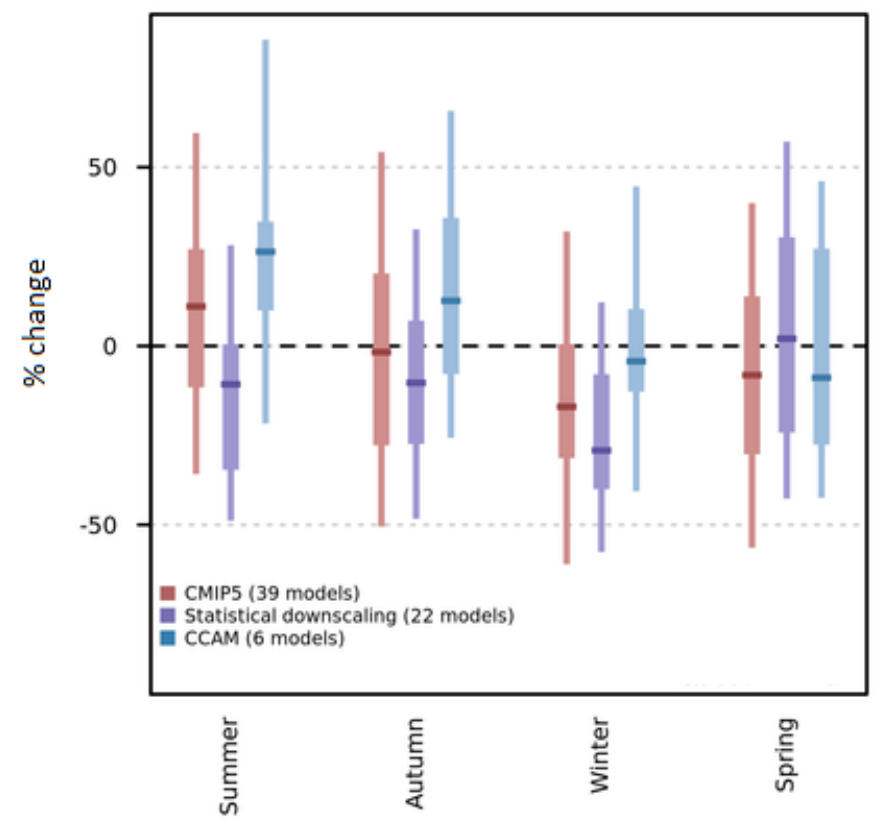


Table 4 Projected future changes in rainfall for southeast QLD and northeast NSW, based on a high forcing scenario RCP8.5 towards the end of the $21^{\text {st }}$ Century. A likelihood descriptor (and corresponding percentage chance of occurrence) is shown for three different outcomes: increase, little change or decrease in rainfall.

\begin{tabular}{lll}
\hline & Southeast $Q L D$ & Northeast NSW \\
\hline \multirow{3}{*}{ Summer } & Increase: unlikely (0-33\%) & Increase: as likely as not (33-66\%) \\
& Little change: as likely as not (33-66\%) & Little change: as likely as not (33-66\%) \\
& Decrease: as likely as not (33-66\%) & Decrease: as likely as not (33-66\%) \\
\hline \multirow{3}{*}{ Autumn } & Increase: unlikely (0-33\%) & Increase: unlikely (0-33\%) \\
& Little change: as likely as not (33-66\%) & Little change: as likely as not (33-66\%) \\
& Decrease: as likely as not (33-66\%) & Decrease: unlikely (0-33\%) \\
\hline \multirow{3}{*}{ Winter } & Increase: unlikely (0-33\%) & Increase: very unlikely (0-10\%) \\
& Little change: as likely as not (33-66\%) & Little change: unlikely (0-33\%) \\
& Decrease: as likely as not (33-66\%) & Decrease: likely (66-100\%) \\
\hline \multirow{3}{*}{ Spring } & Increase: unlikely (0-33\%) & Increase: unlikely (0-33\%) \\
& Little change: as likely as not (33-66\%) & Little change: as likely as not (33-66\%) \\
& Decrease: as likely as not (33-66\%) & Decrease: as likely as not (33-66\%) \\
\hline
\end{tabular}

Table 5 The most likely change in future seasonal rainfall projected for southeast Queensland (SE QLD) and northeast New South Wales (NE NSW). Confidence is assigned based on the degree of evidence and agreement.

\begin{tabular}{|c|c|c|c|}
\hline & Limited evidence & Limited-Medium evidence & Medium evidence \\
\hline Medium agreement & $\begin{array}{ll}\text { Low confidence } \\
\bullet \quad \text { SE QLD summer } \\
\text { Small decrease } \\
\text { - } \quad \text { NE NSW summer } \\
\quad \text { Small increase }\end{array}$ & Low-Medium confidence & $\begin{array}{l}\text { Medium confidence } \\
\text { - NE NSW winter } \\
\text { Decrease }\end{array}$ \\
\hline $\begin{array}{l}\text { Low-Medium } \\
\text { agreement }\end{array}$ & Low-Very Low confidence & $\begin{array}{l}\text { Low confidence } \\
-\quad \text { SE QLD winter } \\
\text { Small decrease }\end{array}$ & $\begin{array}{l}\text { Low-Medium confidence } \\
\text { - } \quad \text { SE QLD autumn } \\
\text { Small decrease } \\
\text { - } \quad \text { NE NSW autumn } \\
\text { Little change } \\
\text { - } \quad \text { NE NSW spring } \\
\quad \text { Small decrease }\end{array}$ \\
\hline Low agreement & Very Low confidence & $\begin{array}{l}\text { Low-Very Low confidence } \\
\text { - } \quad \text { SE QLD spring } \\
\text { Small decrease }\end{array}$ & Low confidence \\
\hline
\end{tabular}

The outcomes of this review and synthesis method indicate a range of confidence levels from Medium Confidence (in a decrease in winter rainfall for northeast NSW) to Low-Very Low confidence (in a small decrease in spring rainfall for southeast QLD). All other cases have either Low confidence, or Low-medium confidence, in a small decrease in rainfall (i.e. 5 to $15 \%$ change), with the exception of northeast NSW for which there is Low confidence in a small increase in summer rainfall.

\section{Discussion and Conclusions}

A novel method was presented for assessing confidence in projections. The method was based on summarising a broad range of factors relating to rainfall in Australia's central eastern seaboard, with a synthesis of this summary used to provide a comprehensive assessment of the degree of confidence in projections of future rainfall.

The assessment shows that a future decrease or increase in rainfall is plausible for any season in southeast QLD and northeast NSW. The confidence estimates for the most likely outcome range from Medium to Low-Very Low, indicating considerable response uncertainties (i.e. relating to the degree of agreement amongst the models for a particular response to a given change in greenhouse gas concentrations). The assessment presented here is primarily focussed on the high emission pathway (RCP8.5), noting that the changes for an intermediate emission pathway (RCP4.5) are typically similar in direction but smaller in magnitude to those of the high emission pathway (Table 3 and Figures 7 and 9). 
Figure 9 Projected changes in rainfall measures, including the mean annual rainfall, annual maximum of daily rainfall and the 20 -year return value of maximum daily rainfall. The projected percentage changes (2080-2099 with respect to the baseline period 1986-2005) are shown for southeast QLD (a) and northeast NSW (b), for the intermediate (blue: RCP4.5) and high (purple: RCP8.5) as well as the baseline period (grey). The central horizontal bar represents the median of the model ensemble, with the shaded region representing the $10^{\text {th }}$ to $90^{\text {th }}$ percentile range.

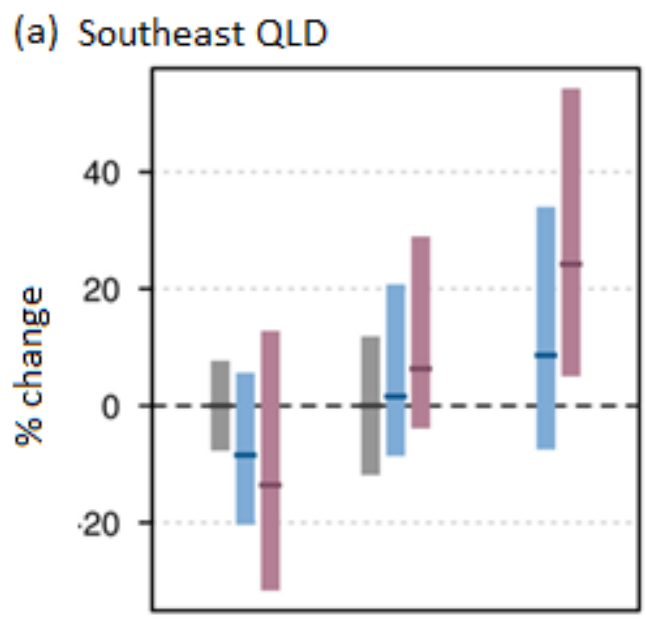

(b) Northeast NSW

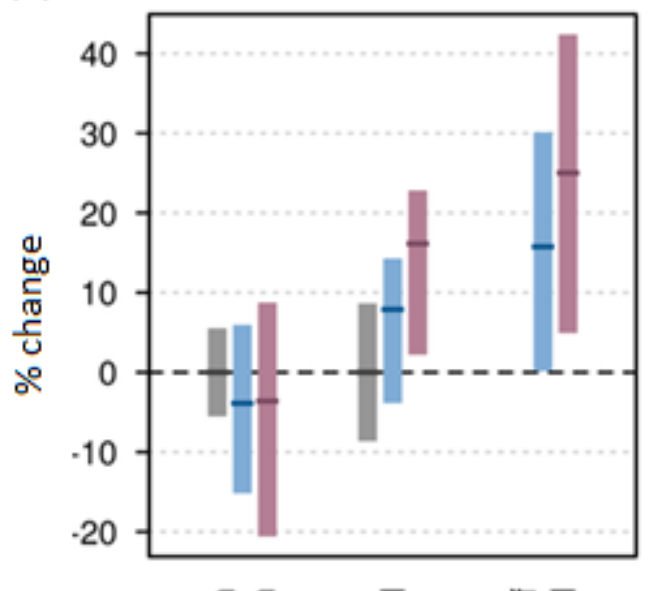

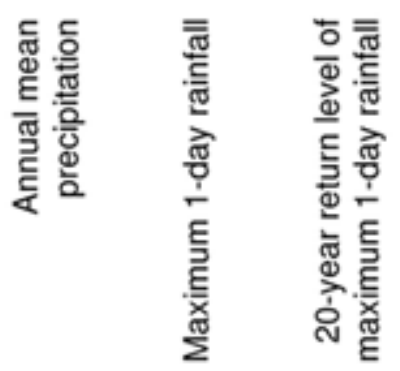


In addition to response uncertainties and greenhouse gas-related scenario uncertainties, there are also considerable natural variability uncertainties. The interannual variability in rainfall in this region from observations and modelling (Figures 4, 6, 7 and 8 ) shows that natural variability is projected to remain significant in comparison to the climate change signal throughout the $21^{\text {st }}$ Century.

In contrast to mean rainfall, a clear increase in the frequency of extreme rainfall is projected for both regions (from Fig. 9), such that there is High confidence in more frequent extreme rainfall events. However, the magnitude of the projected change is less certain than the direction of change, due in part to uncertainties in projected changes to synoptic systems (as discussed in the review section).

Projected changes in some rain-bearing systems (e.g. low pressure systems and fronts) can be related to a range of somewhat inter-related changes to the large-scale circulation, including tropical expansion, a poleward shift of the mid-latitude storm track region and changes to the subtropical and polar jetstreams. Studies of reanalysis and radiosonde data show an expansion of the southern Hadley Cell circulation over the last 30 years (Nguyen et al. 2013; Lucas et al. 2014). However, while poleward expansion of the Hadley circulation is consistent with anthropogenic forcing simulations, comparison between modelling and reanalyses show that modelled changes are significantly different in magnitude than the observed changes in some cases (Hu et al. 2013). This means that the direction of change in these processes is fairly clear but the magnitude of change and associated shift in rainfall are less clear.

Significant uncertainties remain in relation to many of the physical processes influencing rainfall in this region (e.g. current GCMs have difficulty producing accurate representation of tropical cyclones and associated extreme rainfall). However, it is worth noting that the NRM projections (CSIRO and BoM 2015) represent an improvement in confidence from the previous set of projections (CSIRO and BoM 2007). As climate models continue to develop, particularly with respect to horizontal resolution, some uncertainties relating to projections of future regional rainfall may be reduced, while also noting that some uncertainties will remain as a fundamental property of any complex system (e.g., as discussed by Risbey and O'Kane (2011)). In cases where a considerable degree of uncertainty exists, there can be benefits in assessing confidence based on a broad review and synthesis of analyses, as shown here for projections of future rainfall in Australia's eastern seaboard.

\section{Acknowledgements}

Comments on earlier drafts of this manuscript made by Acacia Pepler from the Bureau of Meteorology, as well as Ian Smith and James Risbey from CSIRO, are greatly appreciated.

\section{References}

Allen, J. T., D. J. Karoly and K. J. Walsh, 2014. Future Australian severe thunderstorm environments. Part II: the influence of a strongly warming climate on convective environments. J. Climate, 27, 3848-3868.

Arblaster, J. M. and G. A. Meehl, 2006. Contributions of external forcings to Southern Annular Mode trends. J. Climate, 19, $2896-2905$.

Cai, W. and T. Cowan, 2013. Why is the amplitude of the Indian Ocean Dipole overly large in CMIP3 and CMIP5 climate models? Geophys. Res. Lett., doi:10.1002/grl.50208.

Cai, W., X.-T. Zheng, E. Weller, M. Collins, T. Cowan, M. Lengaigne, W. Yu and T. Yamagata, 2013. Projected response of the Indian Ocean Dipole to greenhouse warming. Nature Geoscience, 6.12, 999-1007.

Callaghan, J. and S. Power, 2010. Variability and decline in the number of severe tropical cyclones making land-fall over eastern Australia since the late nineteenth century. Clim. Dyn., 37, doi:10.1007/s00382-010-0883-2.

Catto, J. L. and S. Pfahl, 2013. The importance of fronts for extreme precipitation, J. Geophys. Res. Atmos., 118, 10,791-10,801, doi:10.1002/jgrd.50852.

Catto, J. L., C. Jakob and N. Nicholls, 2013. A global evaluation of fronts and precipitation in the ACCESS model. Aust. Met. Oceanogr. J., 63, 191-203.

CSIRO and Australian Bureau of Meteorology (BOM), 2007. Climate change in Australia: technical report, Aspendale, Australia, CSIRO Marine and Atmospheric Research.

CSIRO and BoM, 2015. Climate Change in Australia Information for Australia's Natural Resource Management Regions: Technical Report, CSIRO and Bureau of Meteorology, Australia. Available from http://www.climatechangeinaustralia.gov.au/en/publications-library/technicalreport/

Dowdy, A. J. and Y. Kuleshov, 2012. An analysis of tropical cyclone occurrence in the Southern Hemisphere derived from a new satellite-era dataset. Int. J. Remote Sensing, 23, 7382-7397, doi: 10.1080/01431161.2012.685986.

Dowdy, A. J., G. A. Mills, B. Timbal and Y. Wang, 2013a. Changes in the risk of extratropical cyclones in eastern Australia. J. Climate, 26, 1403-1417, doi: 10.1175/JCLI-D-12-00192.1.

Dowdy, A. J., G. A. Mills and B. Timbal, 2013b. Large-scale diagnostics of extratropical cyclogenesis in eastern Australia. Int. J. Climatol., 10, 231802327, doi: $10.1002 /$ joc. 3599 . 
Dowdy, A. J., G. A. Mills, B. Timbal, M. Griffiths and Y. Wang, 2013c. Understanding rainfall projections in relation to extratropical cyclones in eastern Australia. Aust. Met. Oceanogr. J., 63, 355-364.

Dowdy, A. J., G. A. Mills, B. Timbal and Y. Wang, 2014. Fewer large waves for eastern Australia due to decreasing storminess. Nature Climate Change, doi: 10.1038/NCLIMATE2142, 283-286.

Dowdy, A. J., 2014. Long-term changes in Australian tropical cyclone numbers. Atmospheric Science Letters, 15, 4, doi: 10.1002/as12.502.

Dowdy, AJ and Kuleshov, Y, 2014. Lightning climatology of Australia: temporal and spatial variability. Australian Meteorological and Oceanographic Journal, 64, 9-14.

Dowdy, A. and coauthors. 2015. East Coast Cluster Report, Climate Change in Australia Projections for Australia's Natural Resource Management Regions. Available from: http:/www.climatechangeinaustralia.gov.au/media/ccia/2.1.4/cms_page_media/172/ EAST_COAST_CLUSTER_REPORT.pdf.

Drosdowsky, W., 2005. The latitude of the subtropical ridge over eastern Australia: The L index revisited. Int. J. Climatol., 25, $1291-1299$.

Evans, J. P. and coauthors, 2014. Design of a regional climate modelling projection ensemble experiment; NARCliM. Geosci. Model Dev., 7 , 621-629.

Gillett, N. P. and D. W. J. Thompson, 2003. Simulation of recent Southern Hemisphere climate change. Science, 302, 273 - 275.

Grose, M. R., M. J. Pook, P. C. McIntosh, J. S. Risbey and N. L. Bindoff, 2012. The simulation of cutoff lows in a regional climate model: reliability and future trends. Clim. Dyn., 39, 445-459, doi: 10.1007/s00382-012-1368-2.

Grose, M. R., J. Bhend, D. Argueso, M. Ekström, A. Dowdy, P. Hoffman, J. P. Evans and B. Timbal, 2015a Comparison of various climate change projections of eastern Australian rainfall. Aust. Met. Oceanogr. J., 65, 72-89.

Grose, M. R., B. Timbal, L. Wilson, J. Bathols and D. Kent, 2015b. The subtropical ridge in CMIP5 models, and implications for projections of rainfall in southeast Australia. Aust. Met. Oceanogr. J., 65, 90-106.

Guilyardi, E. and coauthors, 2009. Understanding El Niño in ocean-atmosphere general circulation models: progress and challenges. Bull. Amer. Met. Soc., 90, 325-340.

Hopkins, L. C. and G. J. Holland, 1997. Australian heavy-rain days and associated east coast cyclones 1958-92. J. Climate, 10, 621-35.

Hu, Y., L. Tao and J. Liu, 2013. Poleward expansion of the Hadley circulation in CMIP5 simulations. Advances in Atmospheric Sciences, 30, 790-795.

IPCC, 2013. Climate Change 2013. The Physical Science Basis. Contribution of Working Group I to the Fifth Assessment Report of the Intergovernmental Panel on Climate Change. In: Stocker, T. F., D. Qin, G.-K. Plattner, M. Tignor, S. K. Allen, J. Boschung, A. Nauels, Y. Xia, V. Bex and P. M. Midgley (ed.).

Jacob, D., Bärring, L., Christensen, O.B., Christensen, J.H., de Castro, M., Déqué, M.,Giorgi, F., Hagemann, S., Hirschi, M., Jones, R., Kjellström, E., Lenderink, G.,Rockel, B., Sánchez, E., Schär, C., Seneviratne, S.I., Somot, S., van Ulden, A. and B. van den Hurk, 2007. An intercomparison of regional climate models for Europe: model performance in present-day climate. Climatic Change, 81, 31-52.

Ji, F., J.P. Evans, D. Argüeso, L. Fita and A. Di Luca, 2015: Using large-scale diagnostic quantities to investigate change in East Coast Lows. Clim. Dyn., doi: 10.1007/s00382-015-2481-9.

Jones, D.A., W. Wang and R. Fawcett, 2009. High-quality spatial climate data sets for Australia. Aust. Met. Oceanogr. J., 58, 233-48.

Kent, D. M., D. G. C. Kirono, B. Timbal and F. H. S. Chiew, 2013. Representation of the Australian sub-tropical ridge in the CMIP3 models. Int. J. Climatol., 33, 48-57, doi: 10.1002/joc.3406.

King, A. D., L. V. Alexander and M. G. Donat, 2013. The efficacy of using gridded data to examine extreme rainfall characteristics: a case study for Australia. Int. J. Climatol., 33: 2376-2387. doi: 10.1002/joc.3588

Knutson, T. R., J. L. McBride, J. Chan, K. Emanuel, G. Holland, C. Landsea, I. Held, J. P. Kossin, A. K. Srivastava and M. Sugi, 2010. Tropical cyclones and climate change. Nature Geoscience, 3, 157-163, doi:10.1038/ngeo779.

Kuleshov, Y., D. Mackerras and M. Darveniza, 2006. Spatial distribution and frequency of lightning activity and lightning flash density maps for Australia. J. Geophys. Res., 111, D19105, doi:10.1029/2005JD006982.

Kuleshov Y., R. Fawcett, L. Qi, B. Trewin, D. Jones, J. McBride and H. Ramsay, 2010. Trends in TCs in the South Indian Ocean and the South Pacific Ocean. J. Geophys. Res., 115, D01101, doi:10.1029/2009JD012372.

Lavender, S. L. and D. J. Abbs, 2013. Trends in Australian rainfall: contribution of tropical cyclones and closed lows. Clim. Dyn., 40, $317-326$.

Liu, L., W. Yu, and T. Li, 2011. Dynamic and Thermodynamic Air-Sea Coupling Associated with the Indian Ocean Dipole Diagnosed from 23 WCRP CMIP3 Models. J. Climate, 24, 4941-4958.

Lucas, C., B. Timbal and H. Nguyen, 2014. The expanding tropics: a critical assessment of the observational and modelling studies. WIREs Clim. Change, 5, 89-112, doi: 10.1002/wcc.251.

Mastrandrea M., and coauthors, 2010. Guidance note for lead authors of the IPCC fifth assessment report on consistent treatment of uncertainties. Intergovernmental Panel on Climate Change (IPCC), URL https://www.ipcc-wg1.unibe.ch/guidancepaper/ar5_uncertainty-guidancenote.pdf 
McBride, J. L. and N. Nicholls, 1983. Seasonal relationships between Australian rainfall and the Southern Oscillation. Mon. Wea. Rev., 111, 1998-2004.

McGregor, J. L. and M. R. Dix, 2008. An updated description of the Conformal-Cubic Atmospheric Model. High Resolution Simulation of the Atmosphere and Ocean. K. Hamilton and W. Ohfuchi, Springer, 51-76.

Meehl, G. A. and S. Bony, 2011. Introduction to CMIP5. CLIVAR Exchanges, 16, 4-5.

Mearns, L., W. Gutowski, R. Jones , L. Y. Leung, S. McGinnis, A. Nunes and Y. Qian, 2009. A regional climate change assessment program for North America. EOS, 90, 311-312.

Mills, G. A., R. Webb, N. E. Davidson, J. Kepert, A. Seed and D. Abbs, 2010. The Pasha Bulker east coast low of 8 June 2007. CAWCR Technical Report 23 ,Centre for Australian Weather and Climate Research, Melbourne.

Min, S. K., X. Zhang, F. Zwiers and G. C. Hegerl, 2011. Human contribution to more-intense precipitation extremes. Nature, 470, 378-381.

Moise, A., R. Colman and J. Brown, 2012. Behind uncertainties in projections of Australian tropical climate: Analysis of 19 CMIP3 models. J. Geophys. Res., 117. doi: 10.1029/2011JD017365.

Moss, R. H., and coauthors., 2010. The next generation of scenarios for climate change research and assessment. Nature, 463, 747-756.

Nguyen, H., A. Evans, C. Lucas, I. Smith and B. Timbal, 2013. The Hadley Circulation in Reanalyses: Climatology, Variability, and Change. J. Climate, 26, 3357-3376.

Nicholls N, J. L. McBride and R. J. Ormerod, 1982. On predicting the onset of the Australian wet season at Darwin. Mon. Wea. Rev., 110, 1417 .

Nicholls, N., C. Landsea and J. Gill, 1998. Recent trends in Australian region tropical cyclone activity. Meteorology and Atmospheric Physics, 65, 197-205.

Pepler, A., A. Coutts-Smith and B. Timbal, 2014. The role of East Coast Lows on rainfall patterns and inter-annual variability across the East Coast of Australia. Int. J. Climatol., 34, 1011-1021.

Pook, M. J. and T. Gibson, 1999. Atmospheric blocking and storm tracks during SOP-1 of the FROST Project. Australian Meteorological Magazine, (June Special Edition), 51-60.

Pook, M. J., J. S. Risbey, P. C. McIntosh, C. C. Ummenhofer, A. G. Marshall and G. A. Meyers, 2013. The Seasonal Cycle of Blocking and Associated Physical Mechanisms in the Australian Region and Relationship with Rainfall. Mon. Wea. Rev., 141, 4534-4553.

Power, S.B. and G. Kociuba, 2011. What caused the observed twentieth century weakening of the Walker Circulation? J. Climate, 24, 65016514.

Randall, D. A., et al., 2007. Climate Models and Their Evaluation. Climate Change 2007: The Physical Science Basis. Contribution of Working Group I to the Fourth Assessment Report of the Intergovernmental Panel on Climate Change, S. Solomon, et al., Eds., Cambridge University Press, 589-662.

Raphael, M. N. and M. M. Holland, 2006. Twentieth century simulation of the southern hemisphere climate in coupled models. Part 1: large scale circulation variability. Clim. Dyn., 26, 217-228.

Risbey, J. S., P. J. Lamb, R. L. Miller, M. C. Morgan and G. H. Roe, 2002. Exploring the structure of regional climate scenarios by combining synoptic and dynamic guidance and GCM output. J. Climate, 15, 1036-1050.

Risbey, J., M. Pook, P. McIntosh, M. Wheeler and H. Hendon, 2009. On the Remote Drivers of Rainfall Variability in Australia. Mon. Wea. Rev., 137, 3233-3253.

Risbey, J. S. and T. J. O'Kane, 2011. Sources of knowledge and ignorance in climate research. Climatic Change, 108, 755-773.

Saji, N. H., S. P. Xie and T. Yamagata, 2006. Tropical Indian Ocean variability in the IPCC twentieth-century climate simulations. J. Climate, 19, 4397-4417.

Sherwood, S. C., R. Roca, T. M. Weckwerth and N. G. Andronova, 2010. Tropospheric water vapour, convection, and climate. Reviews of Geophysics, 48, doi: 10.1029/2009RG000301.

Smith, I., J. Syktus, C. McAlpine and K. Wong, 2013. Squeezing information from regional climate change projections - results from a synthesis of CMIP5 results for south-east Queensland, Australia. Climatic Change, 121, 609-619, doi: 10.007/s10584-013-0956-4..

Son, S. W., et al., 2010. Impact of stratospheric ozone on Southern Hemisphere circulation change: A multimodel assessment. J. Geophys. res, 115, D00M07.

Speer, M. S., P. Wiles and A. Pepler, 2009. Low pressure systems off the New South Wales coast and associated hazardous weather: establishment of a database. Aust. Met. Oceanogr. J, 58, 29-39.

Sperber, K., and coauthors., 2013. The Asian Summer Monsoon: An Intercomparison of CMIP-5 vs. CMIP-3 Simulations of the Late $20^{\text {th }}$ Century. Clim. Dyn., 41, 2711-2744, doi:10.1007/s00382-012-1607-6.

Taylor, K. E., R. J. Stouffer and G. A. Meehl, 2012. An overview of CMIP5 and the experiment design. Bull. Amer. Met. Soc., 93, $485-498$.

Thompson, D. W. and S. Solomon, 2002. Interpretation of recent Southern Hemisphere climate change. Science, 296, 895-899. 
Timbal, B. and B. J. McAvaney, 2001. An analogue-based method to downscale surface air temperature: application for Australia. Clim. Dyn., $17,947-963$

Timbal, B., Z. Li and E. Fernandez, 2008. The Bureau of Meteorology Statistical Downscaling Model Graphical User Interface: user manual and software documentation. CAWCR Technical Report No. 004, Centre for Australian Weather and Climate Research, Melbourne.

Timbal, B., 2010. The climate of the Eastern Seaboard of Australia: a challenging entity now and for future projections. IOP Conf. Ser.: Earth Environ. Sci., 11, 012013.

Timbal, B. and W. Drosdowsky, 2013. The relationship between the decline of South Eastern Australia rainfall and the strengthening of the subtropical ridge. Int. J. of Climatol., 33, 1021:1034, doi:10.1002/joc.3492.

Troup, A. J., 1961. Variations in upper tropospheric flow associated with the onset of the Australian summer monsoon. Indian J. Meteor. Geophys, 12, 217-230.

van der Linden, P. and J. F. B. Mitchell (eds), 2009. ENSEMBLES: climate change and its impacts: summary of research and results from the ENSEMBLES project. Met Office Hadley Centre, FitzRoy Road, Exeter EX1 3PB. Available at http://ensembleseu.metoffice.com/docs/Ensembles_final_report_Nov09.pdf

Van Vuuren, D. P., and coauthors., 2011. The representative concentration pathways: an overview. Climatic Change, 109, 5-31.

Wang, B. and Q. Ding, 2008. Global monsoon: Dominant mode of annual variation in the tropics. Dynamics of Atmospheres and Oceans, 44, $165-183$

Watanabe, M., J. Kug, F. Jin, M. Collins, M. Ohba and A. Wittenberg, 2012. Uncertainty in the ENSO amplitude change from the past to the future. Geophys. Res. Lett, 39, doi: 10.1029/2012GL053305.

Williams, E. R., 2005. Lightning and climate: A review. Atmospheric Research, 76, 272-287. 